\title{
Loss of Histone Deacetylase 2 Improves Working Memory and Accelerates Extinction Learning
}

\author{
Michael J. Morris, Melissa Mahgoub, Elisa S. Na, Heena Pranav, and Lisa M. Monteggia \\ Department of Psychiatry, University of Texas Southwestern Medical Center, Dallas, Texas 75390-9070
}

Histone acetylation and deacetylation can be dynamically regulated in response to environmental stimuli and play important roles in learning and memory. Pharmacological inhibition of histone deacetylases (HDACs) improves performance in learning tasks; however, many of these classical agents are "pan-HDAC" inhibitors, and their use makes it difficult to determine the roles of specific HDACs in cognitive function. We took a genetic approach using mice lacking the class I HDACs, HDAC1 or HDAC2, in postmitotic forebrain neurons to investigate the specificity or functional redundancy of these HDACs in learning and synaptic plasticity. We show that selective knock-out of $H d a c 2$ led to a robust acceleration of the extinction rate of conditioned fear responses and a conditioned taste aversion as well as enhanced performance in an attentional set-shifting task. Hdac2 knock-out had no impact on episodic memory or motor learning, suggesting that the effects are task-dependent, with the predominant impact of HDAC2 inhibition being an enhancement in an animal's ability to rapidly adapt its behavioral strategy as a result of changes in associative contingencies. Our results demonstrate that the loss of HDAC2 improves associative learning, with no effect in nonassociative learning tasks, suggesting a specific role for HDAC2 in particular types of learning. HDAC2 may be an intriguing target for cognitive and psychiatric disorders that are characterized by an inability to inhibit behavioral responsiveness to maladaptive or no longer relevant associations.

\section{Introduction}

Accumulating evidence suggests that dynamic regulation of chromatin structure affects learning and memory, as broad-acting histone deacetylase (HDAC) inhibitors improve learning and ameliorate memory deficits in animal models of neurodegenerative disease (Levenson et al., 2004; Fischer et al., 2007; Lattal et al., 2007; Vecsey et al., 2007; Barrett and Wood, 2008; Morris et al., 2010; Monsey et al., 2011). HDAC proteins promote a transcriptionally inactive chromatin state by removing acetyl groups from histone tail lysine residues. HDACs are typically grouped into four classes based on structural homology, subcellular localization, and tissue-specific expression patterns, and have been implicated in diverse biological processes, including cellular differentiation, development, apoptosis, and synaptogenesis (Haberland et al., 2009). However, only recently have the functional roles of individual HDACs in brain function been addressed (Brunmeir et al., 2009; Guan et al., 2009; Montgomery et al., 2009; Kim et al., 2012).

The class I HDACs, HDAC1 and HDAC2, are localized predominantly in the nucleus and play important roles in neuronal

Received Feb. 26, 2012; revised Feb. 21, 2013; accepted Feb. 26, 2013.

Author contributions: M.J.M., E.S.N., and L.M.M. designed research; M.J.M., M.M., E.S.N., and H.P. performed research; M.J.M., M.M., E.S.N., H.P., and L.M.M. analyzed data; M.J.M., M.M., and L.M.M. wrote the paper.

This work was supported by National Institutes of Health Grant MH081060 to L.M.M. and the Hartwell Foundation Postdoctoral Fellowship to M.J.M. The authors thank Dr. Eric Olson for generously providing the floxed HDAC1 and HDAC2 mice; Drs. Elena Nosyreva, Waseem Akhtar, and Megumi Adachi for helpful comments and suggestions; and Aroon Karra for mouse genotyping.

The authors declare no competing financial interests.

Correspondence should be addressed to Dr. Lisa M. Monteggia, Department of Psychiatry, University of Texas Southwestern Medical Center, 5323 Harry Hines Blvd, Dallas, TX 75390-9070. E-mail: lisa.monteggia@utsouthwestern.edu.

DOI:10.1523/JNEUROSCI.1001-12.2013

Copyright $\odot 2013$ the authors $\quad 0270-6474 / 13 / 336401-11 \$ 15.00 / 0$ differentiation and brain development; however, their relevance for adult brain function remains unclear (Montgomery et al., 2009). It was recently shown that neuron-specific overexpression of HDAC2, but not HDAC1, impaired learning and memory in adult mice, whereas embryonic deletion of Hdac2 in the brain enhanced learning, suggesting that HDAC2 inhibition may be a useful strategy in disorders that are marked by cognitive impairments (Guan et al., 2009).

In the present study, we examined the role of HDAC1 and HDAC2 in learning by crossing floxed Hdac1 or Hdac2 mice with calcium-calmodulin kinase II (CaMKII)-Cre transgenic mice to delete these HDACs selectively in the forebrain at approximately postnatal days 10-14 (Chen et al., 2001; Akbarian et al., 2002). With few exceptions, studies that have investigated the impact of HDAC inhibition on cognitive function have used behavioral paradigms that contain a strong aversive component (e.g., Morris Water maze, fear conditioning), leaving it unclear whether HDAC inhibition globally impacts learning or is specific for aversively motivated learning tasks (Levenson et al., 2004; Fischer et al., 2007; Lattal et al., 2007; Vecsey et al., 2007; Barrett and Wood, 2008; Bredy and Barad, 2008; Stefanko et al., 2009; Morris et al., 2010; Monsey et al., 2011).

We characterized the effects of individual Hdacl or Hdac2 knock-out $(\mathrm{KO})$ in distinct appetitive and aversively motivated learning tasks to better define their functions in vivo, as well as further explore the feasibility of targeting HDAC1 or HDAC2 manipulation for the treatment of cognitive disorders. We observed dissociable effects of class I HDAC KOs on learning and synaptic plasticity, with $\mathrm{Hdac2}$, but not $\mathrm{Hdac1} \mathrm{KO}$ promoting enhanced hippocampal LTP and improved learning in a taskspecific fashion. Our results demonstrate that HDAC2 inhibition 
improves an animal's ability to shift its behavioral strategy after changes in environmental contingencies, providing support for the hypothesis that targeting HDAC2 could be an effective strategy for alleviating some forms of cognitive impairment.

\section{Materials and Methods}

Hdacl and Hdac2 KO mouse lines. Floxed Hdacl and Hdac2 lines and the CaMKII-Cre93 line were on a mixed 129/BALBC background that was backcrossed to a C57BL/6 line for at least 10 generations. The CaMKIICre mice express Cre recombinase in forebrain neurons beginning 10-14 d postnatal (Chen et al., 2001). The floxed Hdac1 and Hdac2 lines have been previously reported (Montgomery et al., 2009). Genomic DNA was isolated from tails for genotyping by PCR analysis. The primer sequences used were as follows: Cre, forward (5' -CCC GCA GAA CCT GAAGAT GTT C-3'), reverse (5'-CGG CTA TAC GTA ACA GGGTG-3'); Hdac1, forward (5' -TCT ACC GCC CTC ACA AGG C3'), reverse (5' - ACA GAA CTC AAA CAA GCC ATC-3'); Hdac2, forward (5'-GCG TAC AGT CAA GGA GGC GG-3'), reverse (5'-GCT TCA TGG GAT GAC CCT GGC$\left.3^{\prime}\right)$. For all experiments, control (CTL) mice were wild-type littermates of either $\mathrm{Hdacl}$ or Hdac2 KOs. Adult (8-20 weeks of age) male mice were used in all experiments. Mice were maintained on a $12 \mathrm{~h} \mathrm{light/dark} \mathrm{cycle.}$ Hdacl and Hdac2 KOs and their CTL littermates were run in cohorts for the various behavioral tests. A distinct cohort was tested for (in the following order) open field activity, elevated plus maze, locomotor activity, and rotarod performance. Separate cohorts were tested for spatial object recognition, novel object recognition, and context-dependent fear conditioning. Another cohort underwent spatial and novel object recognition testing and cue-dependent fear conditioning. A distinct cohort of Hdac2 $\mathrm{KO}$ mice and their CTL littermates were tested in an attentional set shifting task followed by conditioned taste aversion learning. Naive mice were used for hippocampal slice electrophysiology and Golgi staining for dendritic spine counts. All experiments were performed and scored by an observer that was blind to mouse genotype. All procedures were approved by the Institutional Animal Care and Use Committee of the University of Texas Southwestern Medical Center.

Fluorescent immunohistochemistry. Mice were perfused, and brains were treated as previously described (Gemelli et al., 2006). Briefly, sections were incubated with rabbit anti-HDAC1 (1:2500; Abcam) or rabbit anti-HDAC2 (1:2000, Abcam) in 3\% normal goat serum, 0.3\% Triton $\mathrm{X}-100$ in PBS, overnight. The sections were rinsed with PBS and then incubated with AlexaFluor-594 goat anti-rabbit fluorescent secondary antibody (1:200; Invitrogen) for $2 \mathrm{~h}$. Sections were rinsed in PBS, dehydrated, and coverslipped, and visualized with epifluorescence microscopy.

Western blot analysis. To confirm region-specific $\mathrm{KO}$, brain regions were dissected out and homogenized in a lysis buffer composed of $25 \mathrm{mM}$ HEPES, pH 7.9, 150 mm NaCl, 1 mm PMSF, 20 mm NaF, 1 mm DTT, 0.1\% NP40, and proteinase inhibitor cocktails (Sigma), and spun down to isolate the lysate. Protein concentrations were determined by Bradford assays, and $20 \mu \mathrm{g}$ of the protein was loaded and resolved on $10 \%$ SDSPAGE gels. The proteins were transferred to nitrocellulose membranes and then blocked with $5 \%$ nonfat milk before incubation with primary antibodies. Dilutions of primary antibodies were 1:2000 for both HDAC1 and HDAC2 (Abcam), 1:50,000 for GAPDH (Cell Signaling Technology), and peroxidase-labeled goat anti-rabbit secondary antibodies were used at 1:2000 (Vector Laboratories). The signals were visualized by enhanced chemiluminescense. The immunoreactivity was quantified using NIH imageJ analysis software.

Locomotor activity. For assessment of locomotor activity, mice were placed in a fresh home cage and locomotor activity was assessed for $2 \mathrm{~h}$ using five photocell beams linked to computer acquisition software (San Diego Instruments).

Elevated plus maze. Mice were placed in the center of a cross-shaped maze (each arm $33 \mathrm{~cm} \times 5 \mathrm{~cm}$ ) that was elevated 2 feet above the floor. The maze was composed of two open arms and two closed arms (closed arm height, $25 \mathrm{~cm}$ ). Each mouse was tested individually, and behavior was monitored for $5 \mathrm{~min}$ with a video tracking system. Time spent in the closed and open arms and the center of the maze was determined using EthoVision software (Noldus Information Technology).
Open field activity. Animals were placed in an open field chamber (width $\times$ length, $39 \times 39 \mathrm{~cm}$ ), and their activity was monitored for $5 \mathrm{~min}$ using EthoVision software, which scored the amount of time spent in the center of the open field $(14 \times 14 \mathrm{~cm})$ and the peripheral zones. Zones of the open field were defined using the video tracking software and separated into a center region, peripheral region $(5 \mathrm{~cm}$, approximately the periphery of the arena), and nonperipheral region (the space between the center and periphery). The experiments were performed in dim lighting.

Context-and cue-dependent fear conditioning. For contextual fear conditioning, Hdacl, Hdac2 $\mathrm{KO}$, and CTL mice were individually tested in operant chambers (Med Associates) composed of an electrifiable stainless steel grid floor and surrounded by a sound-attenuating external chamber. For the acquisition phase, the animals were habituated to the chamber [the conditioned stimulus (CS)] for $2 \mathrm{~min}$, followed by 3 presentations of the shock [the unconditioned stimulus (US); $0.5 \mathrm{~mA}$ shock, $1 \mathrm{~s}$ duration] with an interval of $1 \mathrm{~min}$ between shocks. The mice remained in the chamber for $2 \mathrm{~min}$ before being returned to their home cages. Twenty-four hours later, mice were placed in the same boxes and their behavior was videotaped for $5 \mathrm{~min}$ to assess long-term memory for the CS-US association. Extinction training (i.e., reexposure to the context with no shock) was performed for a total of $5 \mathrm{~d}$ beginning $24 \mathrm{~h}$ after training. Freezing behavior was later scored at $5 \mathrm{~s}$ intervals, with freezing behavior defined as no movement except for respiration.

For cue-dependent fear conditioning, mice were trained via exposure to 3 tone-shock pairings ( $30 \mathrm{~s}$ white noise tone, $90 \mathrm{~dB}$ ). Twenty-four hours after training, mice were placed in a novel environment scented with vanilla odor with no tone or shock for $3 \mathrm{~min}$ (i.e., baseline) followed by $3 \mathrm{~min}$ of the tone. Cue-dependent fear conditioning was determined by subtracting baseline freezing behavior from the freezing observed during the tone. Animals underwent extinction training (i.e., a 3 min baseline period followed by presentations of the tone CS alone for $3 \mathrm{~min}$ ) and were tested for spontaneous recovery. To assess spontaneous recovery, mice were reexposed to the tone CS $5 \mathrm{~d}$ after cessation of extinction training. To determine potential genotypic differences in nociception, at the conclusion of the experiments $\mathrm{Hdacl}$ and Hdac2 KOs and their littermate CTLs were exposed to increasing footshock intensity (range, $0.05-0.45 \mathrm{~mA}$ ) to determine the threshold at which the animal responded by vocalization and by jumping (i.e., all four paws above the grid floor). For context- and cue-dependent fear conditioning, betweengroups differences in long-term memory (i.e., freezing at $24 \mathrm{~h}$ after training) were compared by $t$ test. Further extinction (days 2-5) was analyzed by two-way repeated-measures ANOVA. Spontaneous recovery was analyzed by $t$ test. A separate cohort of Hdac2 $\mathrm{KO}$ mice were tested for short-term context- and cue-dependent fear learning. Training was identical to that described above, except that freezing responses were quantified $\sim 90$ min after training. In these mice, acquisition of the freezing response was scored as percentage of time spent freezing during the $30 \mathrm{~s}$ of the second and third tone-CS presentation during training, with observations made every $5 \mathrm{~s}$ during the tone presentations.

Conditioned taste aversion (CTA) learning task. Hdac2 $\mathrm{KO}$ mice and their CTL littermates were adapted to a restricted drinking schedule of two 15 min drinking sessions per day $(\sim 0900$ and $1600 \mathrm{~h})$ for $7-10 \mathrm{~d}$. On the day of training, the mice were exposed to a $0.5 \%$ saccharin solution for 15 min during the morning drinking session rather than the usual presentation of water. One hour after the onset of saccharin intake, the animals were given either an intraperitoneal injection of $0.14 \mathrm{M}$ lithium chloride ( $\mathrm{LiCl}$ ) to induce malaise (Hdac2 $\mathrm{KO}, n=13$; CTL, $n=10$ ), or $0.9 \%$ saline (Hdac2 KO, $n=9$; CTL, $n=9$ ). Saccharin/water choice tests were given at $48 \mathrm{~h}$ after $\mathrm{LiCl}$ and each subsequent day thereafter for a total of $5 \mathrm{~d}$ to determine any genotypic effects on acquisition or extinction of the CTA. At the conclusion of the experiment, animals were given a $0.04 \%$ quinine/water choice test to assess potential differences in taste sensitivity. Differences in saccharin-to-water intake ratios between groups at acquisition (i.e., at $48 \mathrm{~h}$ ) were analyzed by $t$ test; extinction (intake tests 2-5) was assessed by two-way repeated ANOVA.

Rotarod test. To test motor coordination and learning, mice were exposed to 8 rotarod trials across $2 \mathrm{~d}$ ( 4 trials per day). Each mouse was placed on a rotating rod (IITC Life Science), which gradually increased 
speed over the 5 min trial. Each trial ended when the animal fell off the rod or after $5 \mathrm{~min}$.

Spatial and novel object recognition (SOR/NOR) tasks. Mice were individually tested for spatial (SOR) or novel object recognition (NOR) memory. For SOR, on d 1 and 2 animals were allowed a habituation period of $10 \mathrm{~min}$ to an open field chamber (width $\times$ length, $39 \times 39 \mathrm{~cm}$ ), decorated on the inside walls with distinct visual stimuli (e.g., solid vertical lines, a large star shape). Twenty-four hours later, the mice were returned to the open field. Three identical objects (e.g., metal tubing) were evenly spaced $\sim 8 \mathrm{~cm}$ from the walls of the open field, and the mice were allowed a $10 \mathrm{~min}$ session for exploration of the objects. Twenty-four hours later, the location of one of the three objects was changed and mice were given a $6 \mathrm{~min}$ test to determine the ratio of time spent exploring the moved ("spatial") object to the time spent exploring the other two objects. The NOR protocol was similar to the SOR protocol; however, for the object familiarization sessions, three identical objects were presented and on the test day one of the objects was replaced with a novel object (e.g., a metal cone). The ratio of time spent with the novel versus familiar objects was quantified by an observer blind to genotype. In separate SOR and NOR experiments, separate groups of mice were trained for 3 , rather than 10 , min and given a 6 min test $24 \mathrm{~h}$ after training and tested $7 \mathrm{~d}$ after training. Animals that did not explore all the objects during the training and test sessions were excluded from the analyses. A separate group of animals ( $n=6$ /group) were used to determine any potential object exploration bias (i.e., whether the animals initially prefer exploring one object vs another). There were no differences in the amount of time spent exploring the different objects used for the experiments (data not shown).

Attentional set-shifting task (ASST). Hdac2 $\mathrm{KO}$ and CTL mice were placed on a food deprivation schedule ( $2.9 \mathrm{~g}$ of food pellets per day) for $7-10 \mathrm{~d}$ before testing to maintain $\sim 85-90 \%$ of their free-feeding weight. The experiments were then performed according to previously described procedures for mice (Garner et al., 2006; Kos et al., 2011) with slight modification. Mice were tested in an open field chamber (width $\times$ length, $39 \times 39 \mathrm{~cm}$ ) with plastic doors separating a starting compartment from the testing arena. Behavioral testing was performed during the dark phase of the light/dark cycle. A food reward (1/8 of Honey Nut Cheerio, Nestle) was available in small flower pots (height, $6 \mathrm{~cm}$; opening, $6.5 \mathrm{~cm}$; Home Depot), which could be distinguished based on two stimulus dimensions: distinct digging media or odor (50 $\mu \mathrm{l}$ of a flavoring essence applied to the external wall).

On $\mathrm{d} 1$ of the experiment, mice were habituated to the apparatus, flower pots, and food reward for $5 \mathrm{~min}$ followed by a shaping procedure to train the animals to explore and dig in the flower pots for a reward (Garner et al., 2006). During shaping, once the mice retrieved the reward, they were allowed to consume it before being returned to the starting compartment. For session 1 (day 2) and session 2 (day 3), each mouse was trained to discriminate between pairs of flower pots that differed in odor and/or the media in which the reward was buried. For each trial, the mouse was placed in the starting compartment and the door was raised to allow entry to the test compartment. Session 1 consisted of five phases: (1) simple discrimination (SD) required the mice to choose between two distinct types of digging media in unscented pots; (2) compound discrimination (CD), in which a choice was made between two types of media in distinctly scented pots; (3) compound discrimination reversal (CDR), in which the correct digging media was switched to the previously incorrect choice; (4) intradimensional shift (IDS), introduced a novel stimulus pair for the digging media; and (5) intradimensional shift reversal (IDSR), in which the correct digging media became the previously incorrect choice. Session 2 consisted of four phases: (1) intradimensional shift 2 (IDS2), same as IDS except with novel media and odors; (2) intradimensional shift reversal 2; (3) extradimensional shift (EDS), which required the mice to choose based on odor; and (4) extradimensional shift reversal, in which the correct odor was switched to the previously incorrect choice. Therefore, the mice were exposed to a series of increasingly difficult paradigms in which they discriminated within a dimension (the media covering the reward) that was relevant from the SD phase until the EDS phase. For the EDS phase, the mouse had to discriminate within a new stimulus dimension (odors) and the previ-
Table 1. Stimulus pairs and protocol for the attentional set-shifting task

\begin{tabular}{|c|c|c|c|}
\hline Phase & Dimension & Discrimination 1 (pot1/pot2) & Discrimination2 (pot1/pot2) \\
\hline \multicolumn{4}{|l|}{ Session 1} \\
\hline SD & Media & Beads/foam & NA \\
\hline$C D$ & Media & $\begin{array}{l}\text { Lavender/raspberry } \\
\text { Beads/foam }\end{array}$ & $\begin{array}{l}\text { Lavender/raspberry } \\
\text { Foam/beads }\end{array}$ \\
\hline CDR & Media & $\begin{array}{l}\text { Lavender/raspberry } \\
\text { Beads/foam }\end{array}$ & $\begin{array}{l}\text { Lavender/raspberry } \\
\text { Foam/beads }\end{array}$ \\
\hline IDS & Media & $\begin{array}{l}\text { Gardenia/strawberry } \\
\text { Pom poms/rocks }\end{array}$ & $\begin{array}{l}\text { Gardenia/strawberry } \\
\text { Rocks/pom poms }\end{array}$ \\
\hline IDSR & Media & $\begin{array}{l}\text { Gardenia/strawberry } \\
\text { Pom poms/rocks }\end{array}$ & $\begin{array}{l}\text { Gardenia/strawberry } \\
\text { Rocks/pom poms }\end{array}$ \\
\hline \multicolumn{4}{|l|}{ Session 2} \\
\hline IDS2 & Media & $\begin{array}{l}\text { Cinnamon/aloe vera } \\
\text { Green disks/carefresh }\end{array}$ & $\begin{array}{l}\text { Cinnamon/aloe vera } \\
\text { Carefresh/green disks }\end{array}$ \\
\hline IDSR2 & Media & $\begin{array}{l}\text { Cinnamon/aloe vera } \\
\text { Green disks/carefresh }\end{array}$ & $\begin{array}{l}\text { Cinnamon/aloe vera } \\
\text { Carefresh/green disks }\end{array}$ \\
\hline EDS & Odor & $\begin{array}{l}\text { Vanilla/green tea } \\
\text { Easter grass/aluminum balls }\end{array}$ & $\begin{array}{l}\text { Vanilla/green tea } \\
\text { Aluminum balls/Easter grass }\end{array}$ \\
\hline EDSR & Odor & $\begin{array}{l}\text { Vanilla/green tea } \\
\text { Easter grass/aluminum balls }\end{array}$ & $\begin{array}{l}\text { Vanilla/green tea } \\
\text { Aluminum balls/Easter grass }\end{array}$ \\
\hline
\end{tabular}

EDSR, Extradimensional shift reversal; NA, not applicable.

ously relevant dimension (media) became irrelevant. For the first 3 trials of each phase, even after an incorrect choice, the door remained open and the mouse was allowed to retrieve and consume the food reward. On subsequent trials, the door remained closed; if the mouse began digging in the unbaited container, an error was recorded, the trial was terminated, and the mouse was returned to the starting compartment. The flower pot containing the food reward was randomly placed on the right or left side of the test area for each trial. Each mouse had to reach a criterion of eight correct choices (often consecutive trials) to complete each phase. The task protocol and stimulus pairs used are shown in Table 1.

Hippocampal slice recordings. Transverse slices of the hippocampus (HC) were prepared as described previously (Na et al., 2012). Extracellular stimuli were delivered by placing a bipolar platinum-tungsten electrode at the border of CA3 and CA1 along the Schaffer collateral pathway of the HC (Isolated Pulse Stimulator, Model 2100, A-M Systems). Field EPSPs (fEPSPs) were recorded by an aCSF-filled glass electrode (Sutter Instruments). Electrical signals were amplified (AC Amplifier, Model 1800 , A-M Systems), digitized, and stored on a PC for subsequent analysis using Labview version 8.6 software (National Instruments). The input-output relationship was determined by providing an ascending series of stimulus input intensities (range, 40 to $240 \mu \mathrm{A}$ ) until the maximum amplitude response was determined. An input stimulus intensity that induced $40-50 \%$ of the maximum response was used for measuring paired-pulse facilitation (PPF) and LTP. PPF, a measure of short-term presynaptic plasticity, was induced by giving 2 pulses at decreasing interpulse intervals $(400,200,100,50,30$, and $20 \mathrm{~ms})$ and analyzed by dividing the fEPSP slope of pulse 2 by pulse 1 . After $20 \mathrm{~min}$ of a stable baseline fEPSP slope, LTP was induced by theta burst stimulation ( 3 trains with 3 $100 \mathrm{~Hz}$ bursts per train. Each burst consisted of 5 pulses with an interburst interval of $200 \mathrm{~ms}$ and an intertrain interval of $10 \mathrm{~s}$ ).

Golgi staining and spine counting. Golgi impregnation was performed using the FD Rapid GolgiStain Kit (FD Neurotechnologies). Golgi-Cox (G-C) solution (mixture of A and B solutions from kit) was mixed a minimum of $24 \mathrm{~h}$ before use and stored in a dark place at room temperature. Hdac2 $\mathrm{KO}(n=5)$ and CTL $(n=5)$ mice were anesthetized with Nembutal $(50 \mathrm{mg} / \mathrm{kg})$ and subsequently perfused with $1 \times$ PBS for exsanguination before brain removal. After extraction, brains were immersed in G-C solution for $14-16 \mathrm{~d}$ at room temperature in a dark place (G-C mixture was changed after the initial $18 \mathrm{~h}$ of impregnation). Brains were then transferred to solution $\mathrm{C}(10 \mathrm{ml} / \mathrm{brain})$ and incubated for $48 \mathrm{~h}$ at $4^{\circ} \mathrm{C}$. After incubation in solution $\mathrm{C}$, brains were blocked and cut at room temperature on a vibratome (100 $\mu \mathrm{m}$ sections). Serial sections were mounted onto $0.3 \%$ gelatin-coated slides and air dried for $48 \mathrm{~h}$. Slides were then immersed in deionized water 3 times for 5 min with 
gentle shaking, transferred into a solution of D \& E (Golgi kit) for 5-10 $\min$ at $4^{\circ} \mathrm{C}$, and again rinsed 3 times for $5 \mathrm{~min}$. After dehydration through graded ethanol solutions, slides were cleared with xylene ( 3 times for 5 min) and coverslipped with Permount. Hippocampal CA1 pyramidal cells were examined in the dorsal HC. Only neurons that were isolated from other impregnated cells and showed consistent impregnation along the entire length of dendrite were used for analysis. Cells were traced at $100 \times$ magnification using Neurolucida software, and subsequent analyses were performed using Neuroexplorer (MBF Bioscience). The number of spines for the first 3 dendritic branches were quantified for all selected neurons, with 4 neurons counted per animal based on methods described previously (Otto et al., 1991).

Statistical analyses. Data were analyzed by Student's $t$ tests or by mixedmodel or one-way ANOVAs with post hoc Fischer's LSD tests conducted where necessary. Input-output slopes generated from hippocampal slice recordings were fit by linear regression, and the statistical significance of slope differences was determined by $t$ test. Slopes that did not achieve a fit of $r^{2}>0.80$ were discarded from the analysis. A $p$ value of $\leq 0.05$ was considered statistically significant in all experiments.

\section{Results}

\section{Assessment of HDAC1 and HDAC2 deletion}

To determine the regional distribution of the HDAC1 and HDAC2 deletion, we performed immunohistochemistry on coronal slices of conditional $\mathrm{Hdacl}$ and $\mathrm{Hdac2} \mathrm{KOs}$ and littermate CTL mice. At 8 weeks of age, conditional Hdac1 KO mice showed a reduction in $\mathrm{Hdacl}$ expression in forebrain regions, including the HC and prefrontal cortex (PFC) compared with CTL, with no differences in expression in the cerebellum (CBL) (Fig. 1A). Western blot analysis from protein lysates confirmed a significant reduction of HDAC1 in forebrain regions compared with CTL but not in the CBL consistent with a forebrain-specific deletion (Fig. $1 B$ ) as described previously (Chen et al., 2001; Akbarian et al., 2002; Luikart et al., 2005). Similarly, Hdac2 KO mice evidenced a significant reduction in HDAC2 expression in PFC, including the prelimbic and infralimbic regions, as well as $\mathrm{HC}$ and amygdala (AMY) with no change in CBL (Fig. 1C,D). At postnatal d 7, we found no differences in HDAC2 expression in homogenates prepared from whole forebrain in conditional Hdac2 KO mice compared with CTL mice (Fig. 1D), consistent with previous studies reporting that CaMKII-Cre mediated gene deletion occurs postnatally at $\sim 10-14 \mathrm{~d}$ after birth (Chen et al., 2001; Akbarian et al., 2002; Luikart et al., 2005). The conditional Hdacl and Hdac2 $\mathrm{KO}$ mice appeared healthy with no gross impairments and had similar body weights at 8 and at 20 weeks of age compared with littermate CTL mice (data not shown).

\section{Conditional Hdac1 and Hdac2 KO mice exhibit normal locomotor and anxiety-related behavior}

$\mathrm{Hdacl}$ and Hdac2 $\mathrm{KO}$ mice performed similarly to CTL in a $2 \mathrm{~h}$ locomotor activity test (Fig. 2A). To study whether Hdacl or Hdac2 $\mathrm{KO}$ led to an anxiety-like phenotype, we used the elevated plus maze and the open field tests. In both paradigms, mice that spend more time in the open are considered less anxious, in agreement with findings observed after treatment with anxiolytic drugs (Shepherd et al., 1994). In the elevated plus maze, Hdacl and Hdac2 KOs spent a similar amount of time in the center, closed arms, or open arms compared with littermate CTL mice (Fig. $2 B, C$ ), suggestive of no change in anxiety-related behavior. These findings were supported by results obtained in the open field test in which both the Hdacl and Hdac2 $\mathrm{KO}$ mice spent a similar amount of time in the center, nonperiphery, or periphery of the open field compared with CTLs (Fig. 2D,E).

\section{Conditional Hdac2 $\mathrm{KO}$ mice exhibit accelerated extinction of conditioned fear responses}

Given that recent data have demonstrated that embryonic deletion of Hdac2 enhanced hippocampal-dependent learning and memory in contextual fear conditioning and in the Morris Water Maze spatial memory task (Guan et al., 2009), we examined whether postnatal deletion of Hdac2 would produce a similar phenotype. We tested the conditional Hdac1 and Hdac2 KOs in the fear conditioning paradigm, in which animals learn to associate a novel CS with an aversive US, in this case a mild footshock. The performance of Hdac1 $\mathrm{KO}$ mice was indistinguishable from CTLs in both the contextual and cued fear learning paradigms (Fig. $3 A, C$ ). By contrast, Hdac2 $\mathrm{KO}$ mice exhibited enhanced learning in both tests. In contextual fear conditioning, Hdac2 KOs showed enhanced long-term memory of the context-shock pairing as evidenced by increased freezing $24 \mathrm{~h}$ after training $\left(t_{(21)}\right.$ $=2.44, p=0.023$; Figure $3 B$ ). No significant differences were observed between Hdac2 KOs and CTLs at any time point beyond $24 \mathrm{~h}$; however, the KOs exhibited a significant difference in time spent freezing at $48 \mathrm{~h}$ compared with $24 \mathrm{~h}(24-48 \mathrm{~h}=$ $15.81 \pm 3.17)$, compared with CTLs $\left(-0.56 \pm 3.92 ; t_{(21)}=3.28\right.$, $p=0.004)$, suggesting a more rapid extinction rate. In the cuedependent test, we found no difference in long-term memory with a much accelerated rate of extinction compared with CTL mice: there was a significant genotype $\times$ time interaction effect $\left(F_{(3,87)}=3.23, p=0.029\right)$; post hoc LSD tests revealed that Hdac2 KO mice exhibited less freezing at 48 and $72 \mathrm{~h}(p<0.05$; Figure $3 D)$. In the case of both context- and cue-dependent fear conditioning, rate of extinction was best fit by an exponential decay function for $\mathrm{Hdac} 2 \mathrm{KOs}$, whereas extinction rate in CTL mice was best fit by a linear function (Fig. $3 E, F$ ).

Spontaneous recovery is a phenomenon in which a conditioned response that has been extinguished returns after passage of time with no exposure to the CS. An assessment of spontaneous recovery allows for a between-groups distinction between more rapid extinction versus more rapid erasure of the CS-US association. There were no differences in spontaneous recovery between the Hdac1 or Hdac2 $\mathrm{KO}$ mice and their littermate CTLs (Fig. $3 C, D$ ), suggesting that the more rapid extinction observed in Hdac2 $\mathrm{KO}$ mice in the cue-dependent test could not be attributed to an accelerated erasure of fear memory. We also did not observe any differences in threshold sensitivity to footshock in Hdac1 or Hdac2 KOs compared with CTL ruling out betweengroups differences in nociceptive threshold as a confounding factor in our study (data not shown). A separate cohort of mice was used to test short-term fear learning. Hdac2 $\mathrm{KO}$ mice did not exhibit any differences compared with CTL mice in either context- or cue-dependent fear conditioning tested 90 min after training (Fig. 3G). In addition, acquisition of the freezing response during training did not differ between Hdac2 KO and CTL mice, as demonstrated by an equivalent level of freezing to the second and third tone CS (Fig. $3 H$ ), nor did we find any betweengroup difference in freezing after each of the 3 shocks administered during training for contextual fear conditioning (percentage time spent freezing for three $60 \mathrm{~s}$ time bins, after shock: mean \pm SE: CTL $=13.34 \pm 3.33,25.0 \pm 5.1$, and $26.67 \pm$ 7.11 , respectively; Hdac2 $\mathrm{KO}=18.33 \pm 4.1,21.67 \pm 3.51$, and $23.33 \pm 4.6$, respectively).

\section{Hdac2 KO mice more rapidly extinguish a CTA}

We chose to examine the Hdac2 KO mice in the CTA task because of its relative uniqueness among animal learning models; robust learning readily occurs despite long intervals between the CS and 


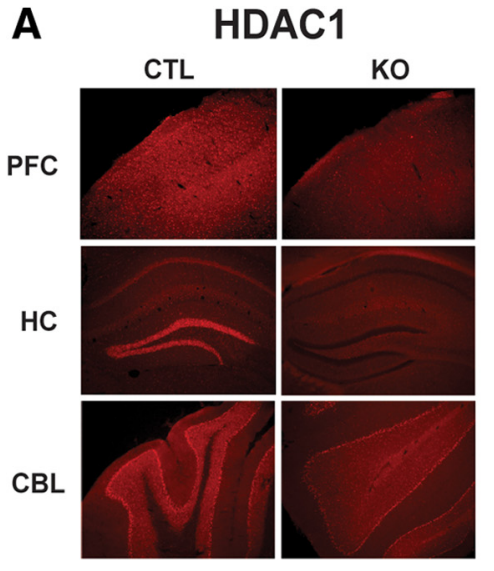

B

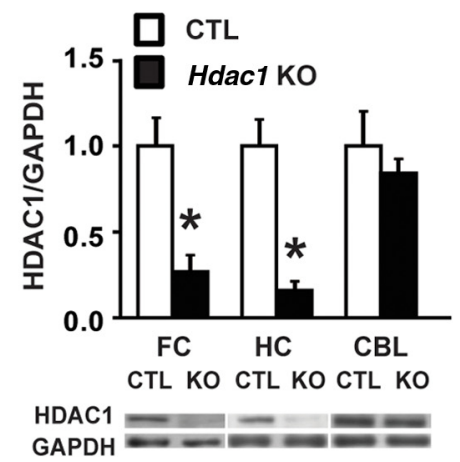

C
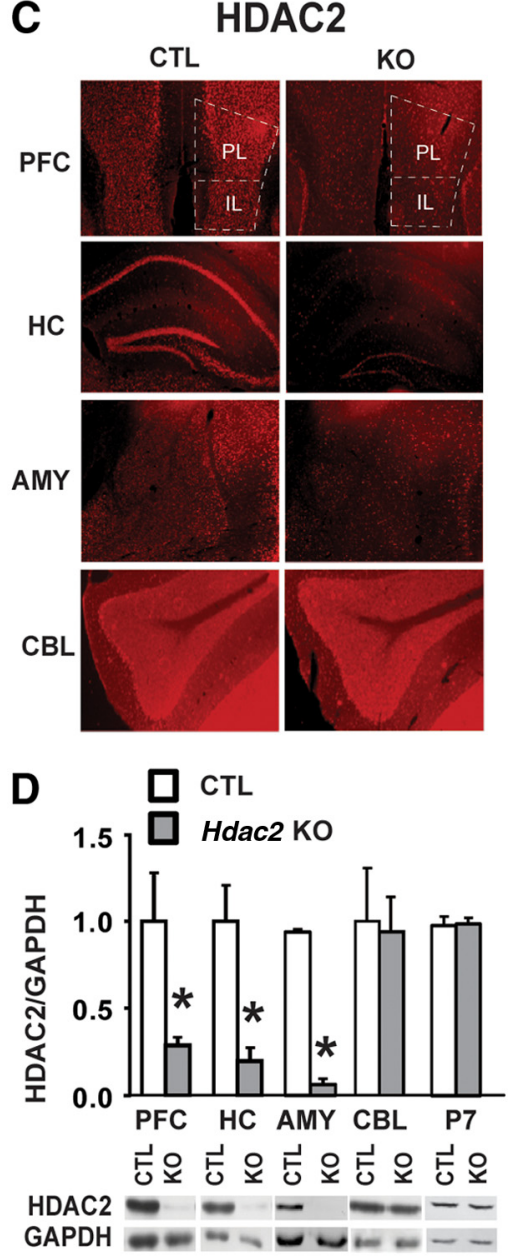

US, and performance in the CTA task requires both classical and operant forms of learning (Bernstein, 1999). Similar to what was observed in the cue-dependent fear conditioning task, Hdac2 $\mathrm{KO}$ mice acquired the CTA similarly to CTL animals; however, they extinguished the classically conditioned association more rapidly than CTL mice (Fig. 3I). A two-way ANOVA with repeated measures determined that there were significant between groups differences in saccharin-to-water intake ratios $\left(F_{(1,91)}=4.514\right.$, $p=0.044)$; however, there was not a significant genotype $\times$ time interaction effect $(p=0.218)$. $t$ tests were conducted to make between-groups comparisons for each intake test and determined that $\mathrm{Hdac} 2 \mathrm{KO}$ mice treated with $\mathrm{LiCl}$ displayed significantly greater saccharin-to-water intake ratios than CTLs treated with $\mathrm{LiCl}$ on day 2 of extinction $\left(t_{(21)}=2.11, p=0.05\right)$. This pattern of elevated saccharin-to-water intake ratios relative to CTL persisted until day 4 of extinction but failed to reach statistical significance on day 3 or 4 ( $p=0.151$ and $p=0.240$, respectively). There were no differences in saline-to-water intake ratios in vehicle-treated Hdac2 KOs versus CTL during any of the intake tests (data not shown). There were no differences in saccharin intakes during training (the drinking session before $\mathrm{LiCl}$ treatment; Fig. 3J) or body weight (grams) between groups before or at the conclusion of the experiment (mean \pm SEM: CTL, before experiment $=29.0 \pm 0.55, \mathrm{KO}=31.02 \pm 0.89$; CTL, conclusion of experiment $=28.86 \pm 0.39, \mathrm{KO}=30.95 \pm 0.81$, data not shown). Also, there was no evidence of any difference in taste sensitivity between $\mathrm{Hdac} 2 \mathrm{KOs}$ and CTLs, as assessed by quinine/water choice test at the conclusion of the experiment (Fig. $3 K$ ).

\section{Conditional $\mathrm{Hdac1}$ or $\mathrm{Hdac} 2 \mathrm{KO}$ mice do not have impaired motor ability on the rotarod test}

In the rotarod test, both $\mathrm{Hdacl}$ and Hdac2 KOs performed similarly to CTLs (Fig. 4A,B). There were no differences between $\mathrm{Hdac1}$ or Hdac2 KOs and their CTL littermates in trial 1, suggesting that the basal motor coordination of both KOs is normal. Furthermore, both Hdac1 and Hdac2 KO learned to stay on the rod at a rate similar to littermate CTLs. These data suggest that forebrain-specific Hdac1 or Hdac2 $\mathrm{KO}$ does not significantly impact motor learning or coordination.

\section{Conditional $\mathrm{Hdac} \mathbf{1}$ or $\mathrm{Hdac} 2$ mice have normal episodic} memory for object location and object form (SOR/NOR) To determine whether postnatal deletion of $\mathrm{Hdacl}$ or Hdac2 impacts long-term episodic memory, we tested mice for SOR and NOR. The SOR task is a hippocampal-dependent task in which evidence of learning is demonstrated by an animal's preference for exploration of a familiar object that has been relocated from a

\footnotetext{
Figure 1. Postnatal forebrain deletion of Hdac1 or Hdac2. A, Immunohistochemistry of coronal sections of 8-week-old mouse brain demonstrates a loss of HDAC1 protein in CaMKII-Cre93-mediated conditional K0 mice relative to littermate (TL mice. Shown are sections of frontal cortex (FC), hippocampus (HC), and cerebellum (CBL). HDAC1 expression was unchanged in $\mathrm{CBL}$, indicative of a forebrain-specific KO. $\boldsymbol{B}$, Western blot analysis confirmed knockdown of HDAC1 in FC and HC to $20-30 \%$ of CTL, but not in CBL. C, Immunohistochemistry images from coronal sections of 8-week-old Hdac2 KO and CTL mice demonstrating loss of HDAC2 protein in PFC, including both prelimbic (PL) and infralimbic (IL) cortex, HC, and amygdala (AMY) but not in the CBL. D, Western blot analysis confirmed a significant reduction of HDAC2 protein in PFC, HC, and AMY ( $~ 70-$ $90 \%$ ) in the conditional KO mice compared with CTL, with no change in CBL. Forebrain levels of HDAC2 protein remained unchanged at postnatal day 7 (P7) in conditional $\mathrm{Hdac2}$ KO mice compared with CTL, confirming a postnatal deletion by our CaMKII-Cre strategy. ${ }^{*} p<0.05$.
} 

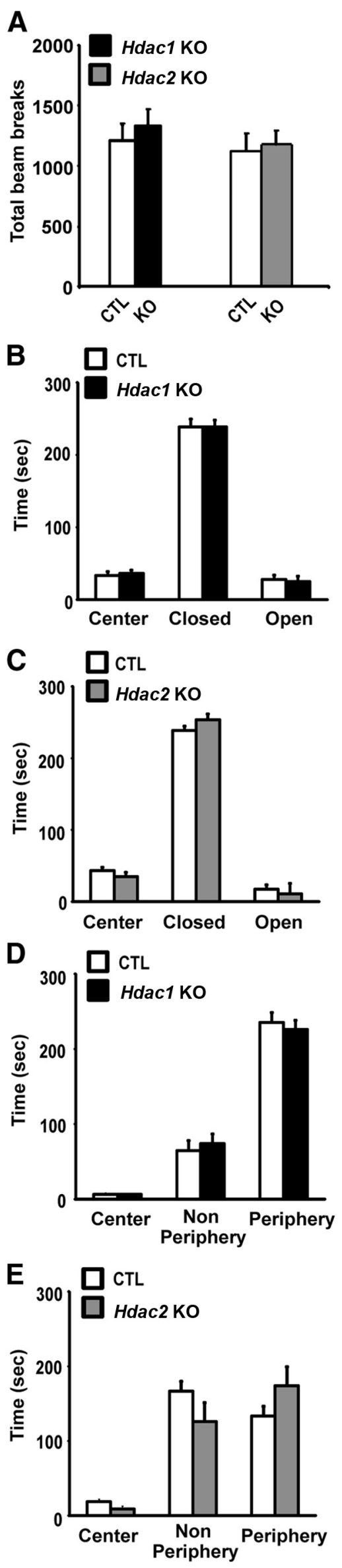

previously learned location in the environment compared with objects that remain in a fixed location (Stupien et al., 2003). Hdac1 KO, Hdac2 $\mathrm{KO}$, and CTL mice preferentially explored a moved object over the nondisplaced objects, as indicated by an increase in the ratio of time spent with the moved object to the other two objects relative to chance performance (Fig. $4 C, D$ ). There were no differences in the ratio of time spent exploring the objects between either KO versus their CTL littermates, suggesting normal memory for spatial recognition in both Hdacl and Hdac2 $\mathrm{KO}$ mice.

The NOR paradigm is a single trial memory test that assesses an animal's ability to discriminate between familiar and unfamiliar (novel) objects. The Hdac1 KO, Hdac2 KO, and CTL mice preferentially explored the novel object compared with the two familiar objects, and the loss of HDAC1 or HDAC2 had no effect on task performance relative to CTL mice (Fig. $3 C, D$ ).

To rule out potential ceiling effects resulting from $10 \mathrm{~min}$ of familiarization with the objects before testing that may have masked any differences in Hdac2 $\mathrm{KO}$ mice relative to CTL mice, we repeated the experiment with another cohort of mice using a 3 min training session for object exploration based on previous data demonstrating that this amount of training is sufficient to induce robust NOR memory in mice treated with broad-acting HDAC inhibitors (Stefanko et al., 2009). When given a 3 min training session for object exploration, there were no differences in the ratio of time spent exploring the objects between $\mathrm{Hdac} 2 \mathrm{KO}$ mice versus their CTL littermates in either SOR or NOR (Fig. $4 D, E)$. Furthermore, compared with 10 min of training, both groups demonstrated less robust learning in both SOR and NOR. Previously, mice treated with pan-HDAC inhibitors have been shown to display evidence of NOR memory when tested $7 \mathrm{~d}$ after training, a time point at which vehicle-treated mice exhibit no memory (Stefanko et al., 2009). We examined the Hdac2 KO and CTL mice given a retention test at $7 \mathrm{~d}$ after training and found they performed near chance level for NOR, suggesting negligible learning (Fig. 4E). Together, the results from SOR and NOR tasks suggest that the loss of HDAC1 or HDAC2 does not impact episodic memory.

Hdac2 KO improves learning in the ASST

Our results in the fear conditioning and CTA tasks suggest that Hdac2 $\mathrm{KO}$ mice more rapidly inhibit behavioral responsiveness to no longer relevant associations. The ASST tests an animal's ability to rapidly shift its response strategy to obtain a food reward, and differs from the fear conditioning and CTA tasks in that it is an appetitively motivated task predominantly based on operant learning principles. Hdac2 $\mathrm{KO}$ mice required fewer trials to complete the task and made fewer errors relative to CTL mice $\left(t_{(15)}=2.40, p=0.031 ; t_{(15)}=2.61, p=0.021\right.$, respectively; Figure $5 B, C$ ). $H d a c 2 \mathrm{KO}$ mice needed significantly fewer trials to reach criterion during several phases of the task. During the CDR, IDSR, IDS2, and EDS phases, Hdac2 $\mathrm{KO}$ mice required fewer trials to reach criterion $\left(t_{(15)}=2.39, p=0.03 ; t_{(15)}=2.17, p=\right.$ $0.047 ; t_{(15)}=2.90, p=0.011 ; t_{(15)}=2.44, p=0.029$, respectively;

$\leftarrow$

Figure 2. Normal locomotor activity and anxiety-like behavior in $\mathrm{Hdac} 1$ and $\mathrm{Hdac} 2 \mathrm{KO}$ mice $A$, Total number of beam beaks in the locomotor activity test in $\mathrm{Hdac} 1$ (black bar, $n=10$ ) and Hdac2 KO (gray bar, $n=10$ ) mice relative to their CTL littermates (CTL, $n=12$ and $n=12$ ) were not significantly different. $\boldsymbol{B}, \boldsymbol{C}$, Time spent by area in the elevated plus maze was not different for $H d a c 1(B, n=10)$ and $H d a c 2(\boldsymbol{C}, n=9)$ KOs relative to their CTL littermates $(n=$ 10 and $n=10)$. $\boldsymbol{D}, \boldsymbol{E}$, Time spent in the zones of the open field chamber were not different between $\operatorname{Hdac1}(\boldsymbol{D}, n=10)$ or Hdac2 $(\boldsymbol{E}, n=10)$ compared with CTL $(n=10$ and $n=10)$. 

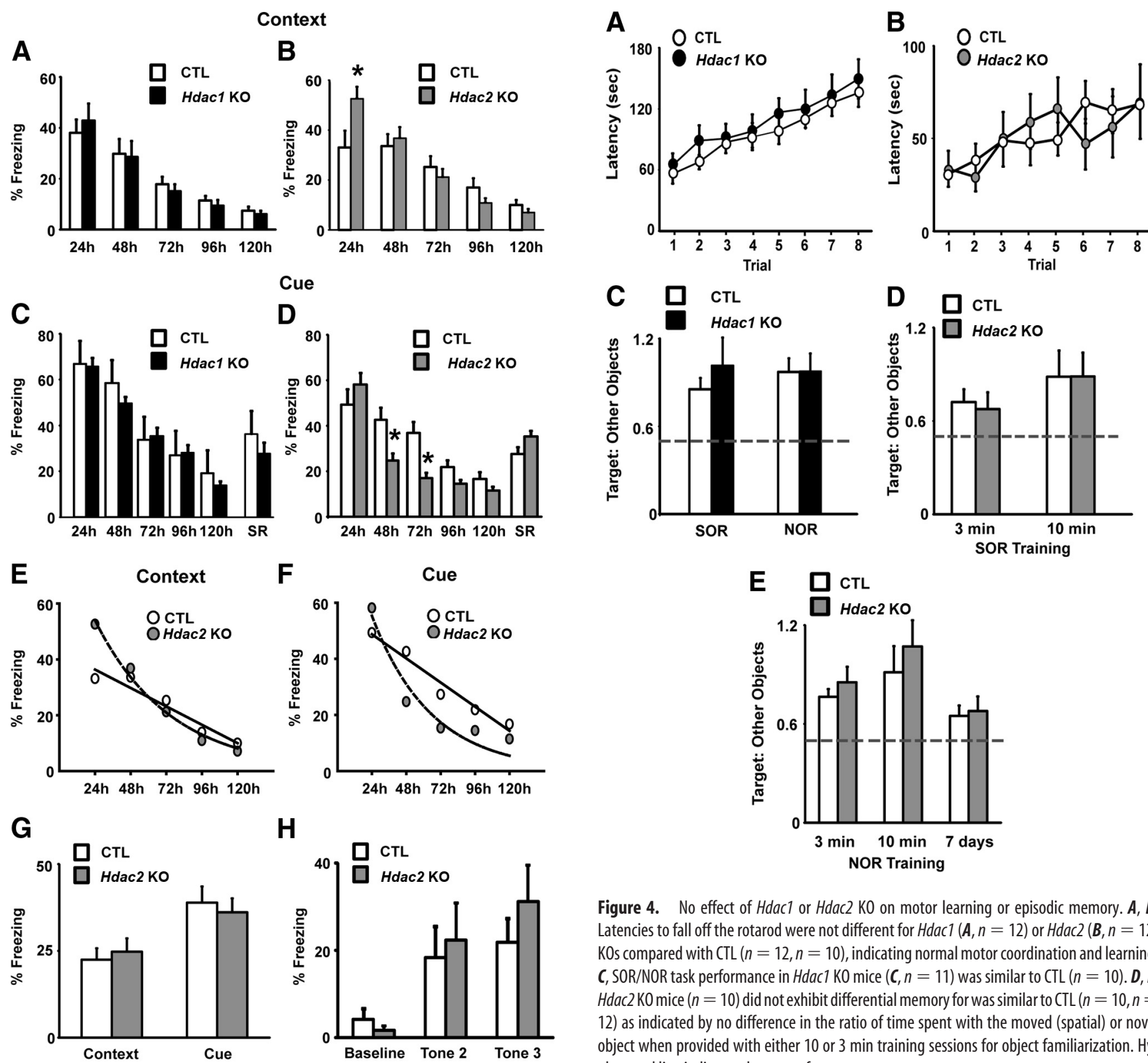

H
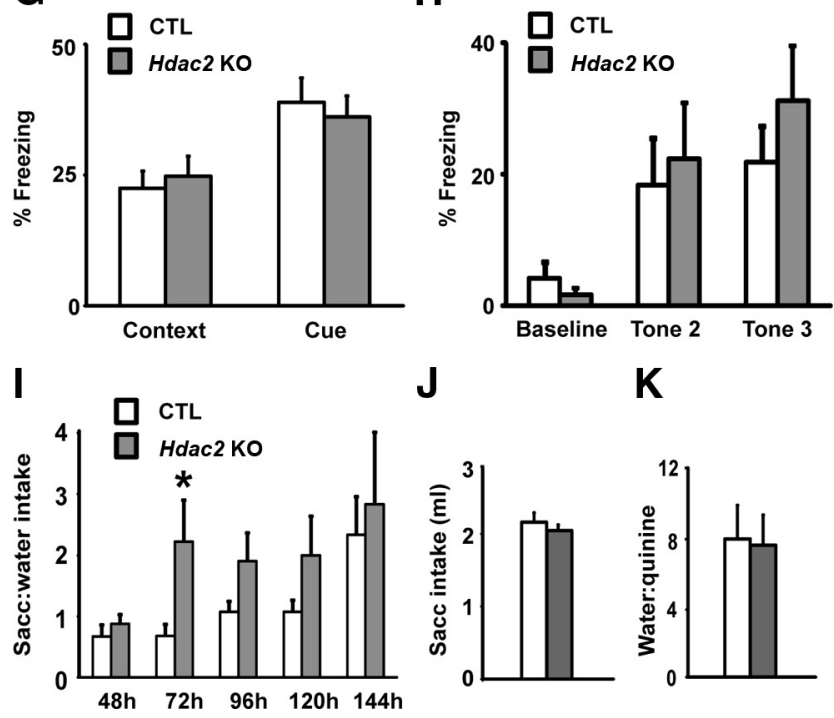

Figure 3. Enhanced classically conditioned associative learning in Hdac2 KO mice. $\boldsymbol{A}, \boldsymbol{B}$,

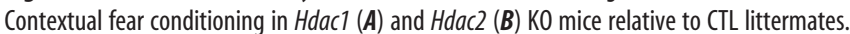
Hdac $1 \mathrm{KO}$ mice $(n=11)$ performed similarly to CTL $(n=12)$. Hdac2 KO mice $(n=13)$ showed an enhanced long-term memory $24 \mathrm{~h}$ after training compared with CTL $(n=10)$. C, $\boldsymbol{D}$, In cue-dependent fear conditioning, $\operatorname{Hdac} 1 \mathrm{KOs}(\boldsymbol{C}, n=11)$ performed similarly to $\mathrm{CTL}(n=9)$, whereas $\mathrm{Hdac} 2 \mathrm{KOs}(\boldsymbol{D}, n=10)$ exhibited an accelerated rate of extinction with no differences in memory tested at $24 \mathrm{~h}$. There were no differences in spontaneous recovery (SR) between groups. $E, F$, Scatterplots with line of best fit showing rate of extinction for Hdac2 $\mathrm{KO}$ mice in contextual $(\boldsymbol{E})$ and cued $(\boldsymbol{F})$ fear conditioning. In both tests, the extinction rate of the CTL mice was best fit by a linear function (solid line), whereas the Hdac2 KOs were best fit by an exponential decay function (hyphenated line), suggesting a more rapid extinction rate in the Hdac2 KOs. Context linear fit $\left(r^{2}\right), C T L=0.936, K 0=0.954$; context exponential decay fit,

$\mathrm{CTL}=0.859, \mathrm{KO}=0.988$; cue linear fit, $\mathrm{CTL}=0.961, \mathrm{KO}=0.724$; cue exponential decay fit, $\mathrm{CTL}=$ $0.955, \mathrm{KO}=0.927$. G, Hdac2 KO mice $(n=10)$ did not display enhancements in short-term contextual or cued fear conditioning measured $90 \mathrm{~min}$ after training compared with CTL ( $n=10)$. H, Hdac2 K0 mice $(n=10)$ exhibited normal acquisition of a freezing response in cued fear conditioning training compared with CTL mice as shown by equivalent levels of freezing during the presentation of the second and third tone CSs during training $(n=10) . I$, Conditioned taste aversion learning in $\mathrm{Hdac2}$ $\mathrm{KO}$ mice expressed as a ratio of $0.5 \%$ saccharin-to-water intake in $\mathrm{Hdac} 2 \mathrm{KO}$ and CTL mice treated with LiCl. Hdac2 KO mice $(n=13)$ displayed significantly greater saccharin-to-water intake ratios relative to $\mathrm{CTL}(n=10)$ at $72 \mathrm{~h}$, and a trend at 96 and $120 \mathrm{~h}$ indicative of more rapid extinction. J, There were no differences in $0.5 \%$ saccharin intakes in $\mathrm{Hdac} 2 \mathrm{KO}$ and CTL mice before LiCl treatment on the day of training. $\boldsymbol{K}$, No difference in water-to-quinine intake ratio indicates that taste sensitivity is normal in

Hdac2 K0s. ${ }^{*} p<0.05$.

Figure 4. No effect of $\mathrm{Hdac} 1$ or $\mathrm{Hdac} 2 \mathrm{KO}$ on motor learning or episodic memory. $\boldsymbol{A}, \boldsymbol{B}$, Latencies to fall off the rotarod were not different for $\operatorname{Hdac1}(\boldsymbol{A}, n=12)$ or $\operatorname{Hdac}(\boldsymbol{B}, n=12)$ KOs compared with CTL ( $n=12, n=10)$, indicating normal motor coordination and learning. C, SOR/NOR task performance in Hdac1 KO mice $(\boldsymbol{C}, n=11)$ was similar to CTL $(n=10) . \boldsymbol{D}, \boldsymbol{E}$ Hdac2 K0 mice $(n=10)$ did not exhibit differential memory for was similar to CTL ( $n=10, n=$ 12) as indicated by no difference in the ratio of time spent with the moved (spatial) or novel object when provided with either 10 or 3 min training sessions for object familiarization. Hyphenated line indicates chance performance.

Figure 5A). Hdac2 mice committed significantly fewer errors during the IDSR and IDS2 phases $\left(t_{(15)}=2.15, p=0.048 ; t_{(15)}=\right.$ $2.58, p=0.021)$ with a strong trend for fewer errors during the CDR and EDS phases ( $p=0.07$ and 0.06 , respectively; data not shown). 
A

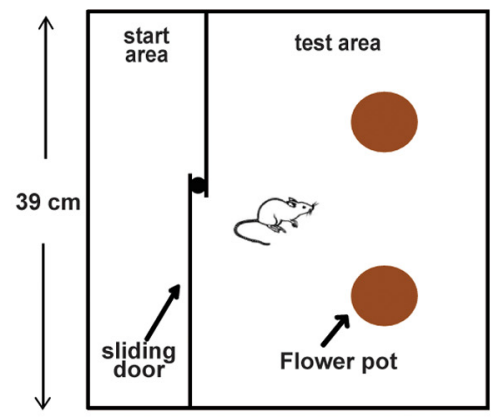

B

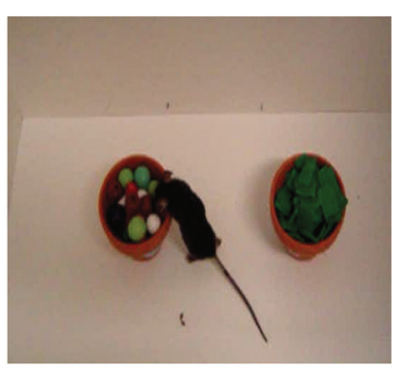

C $\square$ CTL

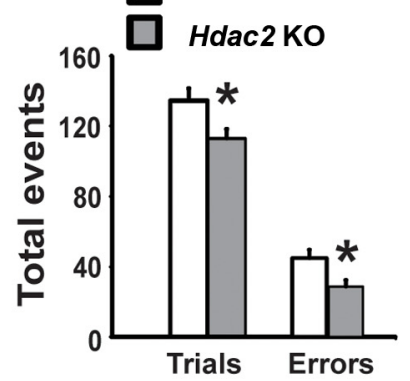

D

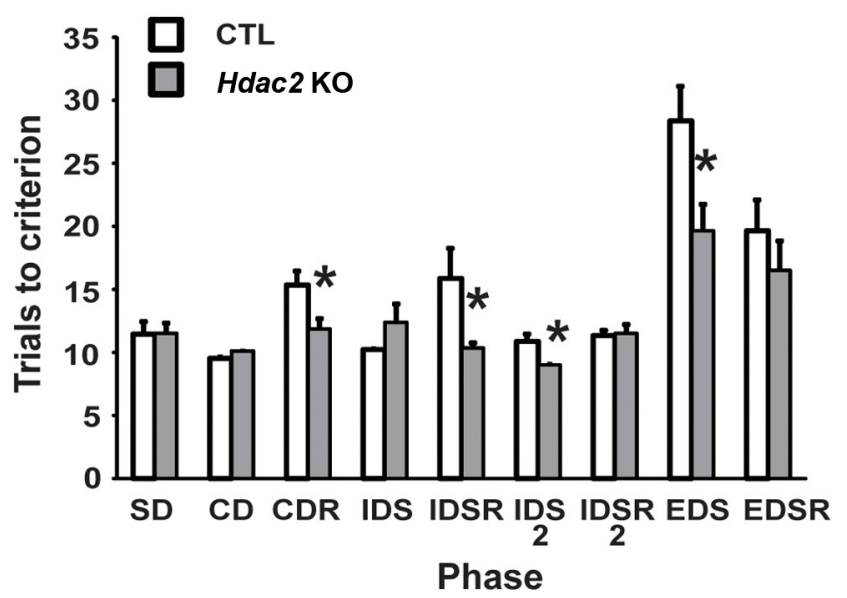

Figure 5. Improved learning in $\mathrm{Hdac} 2 \mathrm{KO}$ mice in the ASST. $A$, Diagram depicting the task. $B, \mathrm{~A}$ mouse making a choice based on digging media during an SD trial. $C$, Total number of errors committed and trials to reach criterion were significantly fewer in the $\mathrm{Hdac} 2 \mathrm{KO}$ mice compared with CTL. D, Trials to reach criterion by phase demonstrating that $\mathrm{Hdac} 2 \mathrm{KO}$ mice $(n=8)$ required fewer trials in the CDR, IDS, intradimensional shift reversal 2 (IDSR2), and EDS phases compared with CTL mice $(n=9) .{ }^{*} p<0.05$.

Hdac2 KO depresses the input-output relationship but enhances LTP magnitude at hippocampal synapses

Hdac1 KO mice exhibited no differences in LTP compared with their littermate CTLs (Fig. 6A). Hdac2 KO, by contrast, led to a robust enhancement of LTP magnitude that was evident for the duration of the recording: genotype $\times$ time interaction $\left(F_{(154,2944)}=2.13, p<\right.$ $0.001)$; all time points after induction of LTP $(p<0.05$, with no significant differences at any time during baseline; Figure $6 B$ ). Although a trend was apparent for depressed input-output slopes in Hdacl KOs, this failed to reach statistical significance ( $p=0.161$; Fig. 6C). Input-output slopes of Hdac2 KOs were significantly depressed relative to CTL mice $\left(t_{(21)}=2.25, p=0.035\right)$, suggesting fewer active synapses upon slice stimulation (Fig. 6D). Hdacl and Hdac2 $\mathrm{KO}$ slices had normal neurotransmitter release probability as assessed by PPF (Fig. 6E,F).
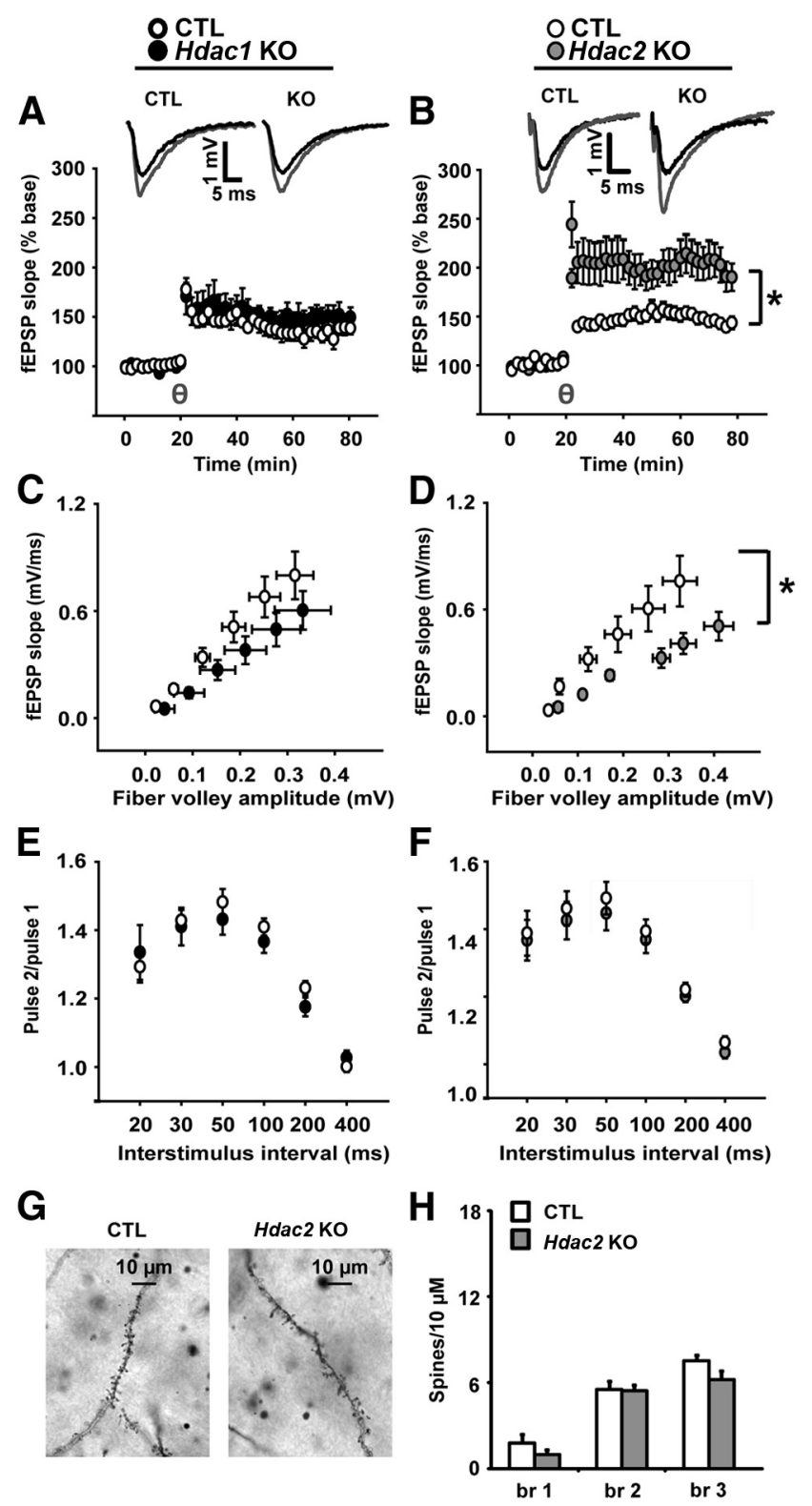

Figure 6. Hippocampal slice properties and dendritic spine counts. $A, \mathrm{LTP}$ induced by $\theta$ burst stimulation was normal in $\mathrm{Hdac} 1 \mathrm{KO}$ compared with $\mathrm{CTL}(\boldsymbol{A})$. $\boldsymbol{B}$, By contrast, $\mathrm{Hdac} 2 \mathrm{KO}$ robustly increased the magnitude of LTP relative to CTL slices. C, D, The input- output slopes in $\mathrm{Hdac} 1 \mathrm{KO}$ slices showed a nonstatistically significant trend toward depression relative to CTL ( $p=0.161$ ). Slopes from $\mathrm{Hdac} 2 \mathrm{KO}$ slices were significantly depressed compared with CTL slices. E, F, PPF was normal in both $\mathrm{Hdac} 1$ and Hdac2 $\mathrm{KO}$ mice. One to 4 slices were used per animal with the following number of slices used for the experiments: for input- output slopes, $\mathrm{Hdac} 1 \mathrm{KO}$ ( $n=$ 16), Hdac2 KO $(n=9)$, CTLs ( $n=17$ and $n=14$, respectively); for PPF, Hdac1 KO $(n=10)$, Hdac2 KO $(n=8)$, CTLs $(n=10$ and $n=8$, respectively); for LTP, Hdac $1 \mathrm{KO}(n=11), \mathrm{Hdac} 2 \mathrm{KO}$ $(n=11)$, CTLs ( $n=9$ and $n=8$, respectively). G, Representative pictures (100X) of dendritic spines in $\mathrm{Hdac} 2 \mathrm{KO}$ and $\mathrm{CTL}$. $\boldsymbol{H}$, There were no differences in number of spines per $10 \mu \mathrm{m}$ for dendrite branch 1 (br 1), br 2, or br 3 in Hdac2 KOs $(n=5)$ compared with CTL ( $n=5)$. Because of a lack of electrophysiological or behavioral phenotype, $\mathrm{Hdac} 1 \mathrm{KO}$ s were not assessed. $\theta=$ induction of LTP by $\theta$ burst stimulation after 20 min of stable baseline. ${ }^{*} p<0.05$.

Hdac2 KOs exhibit normal spine density in hippocampal CA1 We assessed whether there were alterations in spine density in the conditional Hdac2 $\mathrm{KO}$ mice in the CA1 region of the HC. We quantified the number of spines per $10 \mu \mathrm{m}$ within the first three primary branches of pyramidal neurons. This quantification did not reveal an alteration in spine numbers in conditional $\mathrm{Hdac} 2$ KO mice compared with CTLs (Fig. 6G,H). 


\section{Discussion}

The current study demonstrates that postnatal loss of HDAC2 in forebrain neurons improves performance in specific learning and memory tasks. The effects of manipulating individual class I HDACs on complex behavior and synaptic plasticity in adult mice are dissociable as we failed to observe a phenotype in Hdac1 $\mathrm{KO}$ animals. We also demonstrate that postnatal deletion of Hdac2 impacts learning, an important finding consistent with earlier studies that suggest divergent roles for HDAC1 and HDAC2 in mature neurons (Akhtar et al., 2009; Montgomery et al., 2009). Our data are consistent with Guan et al. (2009), showing improved learning after embryonic deletion of Hdac2 in the brain. However, in examining the effects of a postnatal loss of HDAC2, we found important distinctions among different types of learning tasks. Hdac2 $\mathrm{KO}$ mice exhibited improvements in associative learning, including both Pavlovian- and operantbased learning paradigms; however, we found no alterations in these mice when subjected to nonassociative learning tasks, (e.g., SOR, NOR, or rotarod). These data indicate that endogenous HDAC2 does not act as a global restraint on behavioral plasticity in adult animals per se but, instead, has specific, task-dependent influences on performance in learning and memory tasks.

The most salient, and potentially clinically relevant, finding in our study was the robust effect of $\mathrm{Hdac} 2 \mathrm{KO}$ on the extinction of acquired CS-US associations. In the fear learning and CTA tasks, Hdac2 $\mathrm{KO}$ mice extinguished responding for the CS (i.e., context, tone, or saccharin) more rapidly than CTL mice, indicating that forebrain $\mathrm{KO}$ of $\mathrm{Hdac} 2$ lessens the inhibitory influence of previously established associations on new learning (i.e., extinction learning). Post-traumatic stress disorder, anxiety disorders, and phobias are marked by the inability to extinguish fear responses, and their etiology likely involves plasticity in the amygdala; therefore, it is notable that we observed an accelerated rate of extinction in the fear learning and CTA paradigms, which are amygdala-dependent tasks (Welzl et al., 2001; Davis et al., 2006; Poulos et al., 2009; Shin and Liberzon, 2010; Rabinak et al., 2011).

The effects of Hdac2 $\mathrm{KO}$ on distinct types of learning, as well as specific components of associative learning tasks (e.g., extinction, long-term memory), may be the result of differential effects of $\mathrm{Hdac} 2 \mathrm{KO}$ on the functioning of distinct neural circuits that mediate specific forms of learning and/or different stages of memory formation. For example, the amygdala is necessary for cuedependent fear conditioning and plays a role in CTA learning, whereas the $\mathrm{HC}$ is not required for either of these behavioral tasks but is known to be critical for contextual fear learning (Welzl et al., 2001; Sanders et al., 2003; Kim and Jung, 2006; Poulos et al., 2009; Shin and Liberzon, 2010). On the other hand, episodic memory, which requires normal hippocampal functioning (Tulving and Markowitsch, 1998), was not affected by Hdac2 KO. Interestingly, treatment with HDAC inhibitors (Vecsey et al., 2007) as well as inhibition of the class I HDAC and HDAC3 has been shown to improve memory for object recognition (McQuown et al., 2011), highlighting the task-dependent effects on learning after inhibition of specific class I HDACs. We found that learning on the accelerating rotarod, a test of procedural learning that is dependent on the dorsal striatum, was normal in both Hdacl and Hdac2 $\mathrm{KO}$ mice. The ASST is a test of PFC function, a brain region that is critical for normal executive function and may be necessary for extinguishing CS-US associations (Kim and Jung, 2006; Quirk and Mueller, 2008; Sotres-Bayon and Quirk, 2010; Kesner and Churchwell, 2011; Khan and Muly, 2011). In addition, damage to the PFC is known to cause perseverance errors in learning tasks in rodents and humans (Nagahama et al., 2005; Baran et al., 2010). Based on our results in the ASST, we conclude that Hdac2 $\mathrm{KO}$ mice do not perseverate as long as CTL mice, suggesting that the neural substrates underlying executive function may be more labile. This interpretation is consistent with the performance of the Hdac2 KOs in the fear learning and CTA paradigms, as in both cases the KOs display an enhanced ability to inhibit responding to no longer relevant associations. Together, our behavioral results suggest that endogenous HDAC2 limits shifts in behavioral strategy after changes in environmental contingencies, and this is relevant for long-term associative memory (e.g., fear learning, CTA) or attentional set shifting.

In the Hdac2 $\mathrm{KO}$ mice, the observed enhanced synaptic plasticity likely plays a role in the learning phenotype. Although input-output slopes were depressed in Hdac2 KO mice, suggesting fewer activated synapses, we found no significant effect of $\mathrm{Hdac} 2$ $\mathrm{KO}$ on the number of spines per $10 \mu \mathrm{m}$ within the first three primary branches of pyramidal neurons in the hippocampal CA1 subregion. Although this analysis does not rule out the possibility of more subtle changes in spine numbers or the possibility of relatively greater spine formation in $\mathrm{Hdac} 2 \mathrm{KOs}$ after experience in a learning task or LTP induction, it argues against dramatic alterations in spine number as a likely mechanism to account for depressed input-output slopes in hippocampal CA1. The Hdac2 KO mice also had increased magnitude of LTP induced by theta burst, an LTP induction protocol that mimics physiological stimuli (Klemm, 1976; Otto et al., 1991). LTP was facilitated in the $\mathrm{HC}$, a brain region known to be involved in contextual fear learning, a task in which we observed enhanced acquisition in $\mathrm{Hdac2}$ KO mice. However, performance in the SOR task, also dependent on $\mathrm{HC}$, was not influenced by Hdac $2 \mathrm{KO}$, consistent with the hypothesis that Hdac2 $\mathrm{KO}$ may differentially affect the cellular mechanisms responsible for these distinct forms of learning.

By what mechanism does HDAC2 loss result in alterations in synaptic plasticity? We did not directly assess expression of genes involved in dendritic plasticity in our studies. However, previous work from our laboratory assessed the role of HDAC1 and HDAC2 on synapse maturation and synaptic efficacy in hippocampal neurons and found that individual Hdac2 $\mathrm{KO}$ led to deficits in synaptic efficacy in mature neurons (Akhtar et al., 2009). The depressed synaptic input-output curves we observed in the present study may be related to HDAC2's constitutive impact on synaptic efficacy. In addition, an earlier study from our laboratory observed a similar effect of the HDAC inhibitor trichostatin A on synaptic efficacy that could be reversed by coincubation with actinomycin D (Nelson et al., 2006). Together, these findings suggest that the basal decrease in synaptic efficacy seen after loss of HDAC2 may be the result of a transcriptional effect, rather than a transcriptional-independent pathway; however, further experiments are needed to test this hypothesis.

The biological advantages of a chromatin-modifying enzyme that restrains neuronal plasticity and, hence, learning and memory are not clear. Based on a limited number of studies, including our own, deleterious effects of postnatal Hdac2 $\mathrm{KO}$ remain to be found. One important exception is that conditional Hdac2 deletion in adult neural stem cells leads to deficits in neurogenesis in the dentate gyrus subregion of the $\mathrm{HC}$, suggesting a continued role for HDAC2 in cell differentiation in adult brain (Jawerka et al., 2010). Deficits in adult hippocampal neurogenesis have been implicated in mood disorders as well as in a lack of an appropriate behavioral response to antidepressants in animal models, suggesting that the therapeutic potential of targeting 
HDAC2 for cognitive disorders may be limited in some cases (Hanson et al., 2011). It is conceivable that, whereas enhanced plasticity manifests as advantageous in experimental settings in which animals are trained chronologically in distinct learning tasks, in nature such rapid inhibition of responding to CS-US associations could prove maladaptive. As one example, CTA is an adaptive response to ingested poisons; therefore, near immediate extinction to the CS after limited experience in which the US is not present may be considered detrimental. One role of endogenous HDAC2 in the adult brain may therefore be to promote and maintain the stability of learned associations when an organism is faced with new and competing associations; however, this hypothesis demands further study. Recent data suggest that a postnatal forebrain KO of the class II HDAC, Hdac4, impairs learning and LTP, demonstrating dissociable roles for class I versus class II HDACs in cognition and synaptic plasticity (Kim et al., 2012). These data, in conjunction with the present study, indicate that loss of individual HDAC isoforms in adult brain can have widely varying behavioral effects, and suggests caution in the use of broad-acting HDAC inhibitors to target cognitive impairment.

Our data suggest that the prevailing effect of Hdac2 $\mathrm{KO}$ is not to globally enhance de novo learning and memory, as has been previously suggested, but rather to suppress the inhibitory influence of established but no longer relevant associative contingencies. Further studies of HDAC2 function may aid in a better understanding of the molecular mechanisms that contribute to cognitive and psychiatric disorders that are marked by a relative inability to inhibit maladaptive behavioral responses to acquired associations, such as phobia, post-traumatic stress, and compulsive disorders.

\section{References}

Akbarian S, Rios M, Liu RJ, Gold SJ, Fong HF, Zeiler S, Coppola V, Tessarollo L, Jones KR, Nestler EJ, Aghajanian GK, Jaenisch R (2002) Brainderived neurotrophic factor is essential for opiate-induced plasticity of noradrenergic neurons. J Neurosci 22:4153-4162. Medline

Akhtar MW, Raingo J, Nelson ED, Montgomery RL, Olson EN, Kavalali ET, Monteggia LM (2009) Histone deacetylases 1 and 2 form a developmental switch that controls excitatory synapse maturation and function. J Neurosci 29:8288-8297. CrossRef Medline

Baran SE, Armstrong CE, Niren DC, Conrad CD (2010) Prefrontal cortex lesions and sex differences in fear extinction and perseveration. Learn Mem 17:267-278. CrossRef Medline

Barrett RM, Wood MA (2008) Beyond transcription factors: the role of chromatin modifying enzymes in regulating transcription required for memory. Learn Mem 15:460-467. CrossRef Medline

Bernstein IL (1999) Taste aversion learning: a contemporary perspective. Nutrition 15:229-234. CrossRef Medline

Bredy TW, Barad M (2008) The histone deacetylase inhibitor valproic acid enhances acquisition, extinction, and reconsolidation of conditioned fear. Learn Mem 15:39-45. CrossRef Medline

Brunmeir R, Lagger S, Seiser C (2009) Histone deacetylase HDAC1/ HDAC2-controlled embryonic development and cell differentiation. Int J Dev Biol 53:275-289. CrossRef Medline

Chen RZ, Akbarian S, Tudor M, Jaenisch R (2001) Deficiency of methylCpG binding protein-2 in CNS neurons results in a Rett-like phenotype in mice. Nat Genet 27:327-331. CrossRef Medline

Davis M, Myers KM, Chhatwal J, Ressler KJ (2006) Pharmacological treatments that facilitate extinction of fear: relevance to psychotherapy. NeuroRx 3:82-96. CrossRef Medline

Fischer A, Sananbenesi F, Wang X, Dobbin M, Tsai LH (2007) Recovery of learning and memory is associated with chromatin remodelling. Nature 447:178-182. CrossRef Medline

Garner JP, Thogerson CM, Würbel H, Murray JD, Mench JA (2006) Animal neuropsychology: validation of the Intra-Dimensional ExtraDimensional set shifting task for mice. Behav Brain Res 173:53-61. CrossRef Medline

Gemelli T, Berton O, Nelson ED, Perrotti LI, Jaenisch R, Monteggia LM (2006) Postnatal loss of methyl-CpG binding protein 2 in the forebrain is sufficient to mediate behavioral aspects of Rett syndrome in mice. Biol Psychiatry 59:468-476. CrossRef Medline

Guan JS, Haggarty SJ, Giacometti E, Dannenberg JH, Joseph N, Gao J, Nieland TJ, Zhou Y, Wang X, Mazitschek R, Bradner JE, DePinho RA, Jaenisch R, Tsai LH (2009) HDAC2 negatively regulates memory formation and synaptic plasticity. Nature 459:55-60. CrossRef Medline

Haberland M, Montgomery RL, Olson EN (2009) The many roles of histone deacetylases in development and physiology: implications for disease and therapy. Nat Rev Genet 10:32-42. CrossRef Medline

Hanson ND, Owens MJ, Nemeroff CB (2011) Depression, antidepressants, and neurogenesis: a critical reappraisal. Neuropsychopharmacology 36 : 2589-2602. CrossRef Medline

Jawerka M, Colak D, Dimou L, Spiller C, Lagger S, Montgomery RL, Olson EN, Wurst W, Göttlicher M, Götz M (2010) The specific role of histone deacetylase 2 in adult neurogenesis. Neuron Glia Biol 6:93-107. CrossRef Medline

Kesner RP, Churchwell JC (2011) An analysis of rat prefrontal cortex in mediating executive function. Neurobiol Learn Mem 96:417-431. CrossRef Medline

Khan ZU, Muly EC (2011) Molecular mechanisms of working memory. Behav Brain Res 219:329-341. CrossRef Medline

Kim JJ, Jung MW (2006) Neural circuits and mechanisms involved in Pavlovian fear conditioning: a critical review. Neurosci Biobehav Rev 30: 188-202. CrossRef Medline

Kim MS, Akhtar MW, Adachi M, Mahgoub M, Bassel-Duby R, Kavalali ET, Olson EN, Monteggia LM (2012) An essential role for histone deacetylase 4 in synaptic plasticity and memory formation. J Neurosci 32:1087910886. CrossRef Medline

Klemm WR (1976) Physiological and behavioral significance of hippocampal rhythmic, slow activity ("theta rhythm"). Prog Neurobiol 6:23-47. CrossRef Medline

Kos T, Nikiforuk A, Rafa D, Popik P (2011) The effects of NMDA receptor antagonists on attentional set-shifting task performance in mice. Psychopharmacology (Berl) 214:911-921. CrossRef Medline

Lattal KM, Barrett RM, Wood MA (2007) Systemic or intrahippocampal delivery of histone deacetylase inhibitors facilitates fear extinction. Behav Neurosci 121:1125-1131. CrossRef Medline

Levenson JM, O’Riordan KJ, Brown KD, Trinh MA, Molfese DL, Sweatt JD (2004) Regulation of histone acetylation during memory formation in the hippocampus. J Biol Chem 279:40545-40559. CrossRef Medline

Luikart BW, Nef S, Virmani T, Lush ME, Liu Y, Kavalali ET, Parada LF (2005) TrkB has a cell-autonomous role in the establishment of hippocampal Schaffer collateral synapses. J Neurosci 25:3774-3786. CrossRef Medline

McQuown SC, Barrett RM, Matheos DP, Post RJ, Rogge GA, Alenghat T, Mullican SE, Jones S, Rusche JR, Lazar MA, Wood MA (2011) HDAC3 is a critical negative regulator of long-term memory formation. J Neurosci 31:764-774. CrossRef Medline

Monsey MS, Ota KT, Akingbade IF, Hong ES, Schafe GE (2011) Epigenetic alterations are critical for fear memory consolidation and synaptic plasticity in the lateral amygdala. PLoS One 6:e19958. CrossRef Medline

Montgomery RL, Hsieh J, Barbosa AC, Richardson JA, Olson EN (2009) Histone deacetylases 1 and 2 control the progression of neural precursors to neurons during brain development. Proc Natl Acad Sci U S A 106 : 7876-7881. CrossRef Medline

Morris MJ, Karra AS, Monteggia LM (2010) Histone deacetylases govern cellular mechanisms underlying behavioral and synaptic plasticity in the developing and adult brain. Behav Pharmacol 21:409-419. CrossRef Medline

Na ES, Nelson ED, Adachi M, Autry AE, Mahgoub MA, Kavalali ET, Monteggia LM (2012) A mouse model for MeCP2 duplication syndrome: $\mathrm{MeCP} 2$ overexpression impairs learning and memory and synaptic transmission. J Neurosci 32:3109-3117. CrossRef Medline

Nagahama Y, Okina T, Suzuki N, Nabatame H, Matsuda M (2005) The cerebral correlates of different types of perseveration in the Wisconsin Card Sorting Test. J Neurol Neurosurg Psychiatry 76:169-175. CrossRef Medline

Nelson ED, Kavalali ET, Monteggia LM (2006) MeCP2-dependent transcriptional repression regulates excitatory neurotransmission. Curr Biol 16:710-716. CrossRef Medline

Otto T, Eichenbaum H, Wiener SI, Wible CG (1991) Learning-related patterns of CA1 spike trains parallel stimulation parameters optimal for inducing 
hippocampal long-term potentiation. Hippocampus 1:181-192. CrossRef Medline

Poulos AM, Li V, Sterlace SS, Tokushige F, Ponnusamy R, Fanselow MS (2009) Persistence of fear memory across time requires the basolateral amygdala complex. Proc Natl Acad Sci U S A 106:11737-11741. CrossRef Medline

Quirk GJ, Mueller D (2008) Neural mechanisms of extinction learning and retrieval. Neuropsychopharmacology 33:56-72. CrossRef Medline

Rabinak CA, Angstadt M, Welsh RC, Kenndy AE, Lyubkin M, Martis B, Phan KL (2011) Altered amygdala resting-state functional connectivity in post-traumatic stress disorder. Front Psychiatry 2:62. CrossRef Medline

Sanders MJ, Wiltgen BJ, Fanselow MS (2003) The place of the hippocampus in fear conditioning. Eur J Pharmacol 463:217-223. CrossRef Medline

Shepherd JK, Grewal SS, Fletcher A, Bill DJ, Dourish CT (1994) Behavioural and pharmacological characterisation of the elevated "zero-maze" as an animal model of anxiety. Psychopharmacology (Berl) 116:56-64. CrossRef Medline

Shin LM, Liberzon I (2010) The neurocircuitry of fear, stress, and anxiety disorders. Neuropsychopharmacology 35:169-191. CrossRef Medline
Sotres-Bayon F, Quirk GJ (2010) Prefrontal control of fear: more than just extinction. Curr Opin Neurobiol 20:231-235. CrossRef Medline

Stefanko DP, Barrett RM, Ly AR, Reolon GK, Wood MA (2009) Modulation of long-term memory for object recognition via HDAC inhibition. Proc Natl Acad Sci U S A 106:9447-9452. CrossRef Medline

Stupien G, Florian C, Roullet P (2003) Involvement of the hippocampal CA3-region in acquisition and in memory consolidation of spatial but not in object information in mice. Neurobiol Learn Mem 80:32-41. CrossRef Medline

Tulving E, Markowitsch HJ (1998) Episodic and declarative memory: role of the hippocampus. Hippocampus 8:198-204. CrossRef Medline

Vecsey CG, Hawk JD, Lattal KM, Stein JM, Fabian SA, Attner MA, Cabrera SM, McDonough CB, Brindle PK, Abel T, Wood MA (2007) Histone deacetylase inhibitors enhance memory and synaptic plasticity via CREB: CBP-dependent transcriptional activation. J Neurosci 27:6128-6140. CrossRef Medline

Welzl H, D’Adamo P, Lipp HP (2001) Conditioned taste aversion as a learning and memory paradigm. Behav Brain Res 125:205-213. CrossRef Medline 